NBER WORKING PAPERS SERIES

TRADE REFORMS, CREDIBILITY, AND DEVELOPMENT

Joshua Aizenman

Working Paper No. 3600

NATIONAL BUREAU OF ECONOMIC RESEARCH 1050 Massachusetts Avenue

Cambridge, MA 02138

January 1991

Prepared for the fourth meeting of the Interamerican Seminar on Economics, organized by Edmar Bacha and Sebastian Edwards, under the auspices of the National Bureau of Economic Research and the Pontificia Universidade Catolica do Rio de Janeiro. I would like to thank Carsten Kowalczyk and Nancy P. Marion for very useful comments. This paper is part of NBER's research program in International studies. Any opinions expressed are those of the author and not those of the National Bureau of Economic Research. 
NBER Working Paper \#3600

January 1991

\section{TRADE REFORMS, CREDIBILITY, AND DEVELOPMENT}

\section{ABSTRACT}

This paper analyzes the role of investment policies in regimes undergoing trade liberalization with policy makers of uncertain credibility. We consider an economy producing exportable and importable goods. The economy is liberalized, and tariffs are eliminated. The public views the reform credibility as questionable, and expects the possibility of future policy reversal. The policy maker sets policies and public investment as to maximize the expected utility of a risk averse representative agent. We identify the need to tax private investment in the importable sector, and to subsidize private investment in the outward-oriented sector. We show that the signaling effect of public investment may generate a positive externality for public investment in the outward sector, and a negative externality for public investment in the inward-oriented activity. We demonstrate that the elimination of sectorial private investment policies call for a rise in the public/private capital ratio in the outward-oriented activities, and a drop in that ratio in the inward-oriented activities. In the presence of an external credit ceiling, a higher degree of risk aversion increases the magnitude (without changing the nature) of the policies.

Joshua Aizenman Economics Department Dartmouth College Hanover, NH 03755 


\section{Introduction and summary}

Recent discussions have highlighted the adverse effects of policy uncertainty on investment in developing countries: domestic and foreign investors may prefer to wait for the uncertainty to clear itself, or to invest abroad. 1 This may leave the policy maker in the uneasy position, where the private sector will not renew investment and growth as long as credibility is shaky. The policy maker may find himself in the position of Baron von Müchausen, searching for the cheapest way to pull himself out of the mud by griping his own hair. The purpose of this paper is to investigate the degree to which investment policies may work toward reaching this goal. We focus on the case where the policy maker applies the same welfare criteria as the private sector, and attaches the same probabilities to the various events. We would like to demonstrate that, in addition to the standard role of increasing the capital stock, public investment may serve as a signaling device. By investing in the proper activities, the policy maker is bonding himself, conveying an important signal regarding his future intention.

The motivation for this paper stems from several observations. A study by Greene and Villanueva (1990) demonstrated that the rate of private investment in developing countries is positively related to the public sector investment. 2 This begs the question regarding the importance of public and private investment in accounting for growth. This issue may be confirmed more formally, by regressing the growth rate on the private and public investment rates. It turns out that public investment has insignificant importance, whereas private investment plays an important role in accounting for growth. ${ }^{3}$ These observations are

1. On uncertainty and the timing of investment see, for example, van Wijnbergen (1985), Pyndick (1988), Dombusch (1988) and Dixit (1989).

2. Their study uses the data assembled by the world bank on private investment in 23 countries between 1975-1987 [see Pfeffeman and Madarassy (1989)].

3. To verify this point, I analyzed the role of public and private investment of the 23 countries studied by Greene and Villanueva (1990). For details, see Appendix A. For further 
consistent with the view that an important role of public investment is signaling the policy maker's future intention. In regimes whose credibility and reputation are questionable, signaling may require irreversible acts like a sector specific investment. In this paper we explore this possibility for a developing economy facing an endogenous credit ceiling. The signaling role of commercial policies in the presence of incredible policy makers was the topic of Rodrik (1989), who concluded that achieving credibility of commercial reform may require overshooting free trade, actually subsidizing imports. The purpose of our paper is to focus on the signaling role of investment, taking the commercial policy invoked by the reformist administration as given. We consider the case where there are several feasible projects, requiring both public and private investment. Projects may differ in terms of their outwardness (as measured by their impact on the nation's international trade), as well as in terms of the degree of substitutability between public and private investment. In such an economy, irreversible public investment may signal the future design of policies.

For exposition simplicity we consider a minimal framework: a two period, two sector economy. One sector is producing exportable goods, and the second sector is producing importable goods. We refer to these sectors as the outward- and the inward-oriented sectors, respectively. 4 The output in each sector is determined by the available capital. The capital stock is specific to each sector, and is the outcome of past private and public investment. Private investment is financed by local bonds, denominated in terms of the local goods. The economy is small, facing given external terms of trade and an external credit ceiling. A country that will default on its external debt obligations may face impediments to its trade,

discussion regarding the relative role of public investment, see Blejer and Khan (1984) and Khan and Reinhart (1990).

4. This classification stems from the observation that expansion of exportable goods tends to increase the trade dependency of the economy. The opposite applies for expansion of importable goods. 
$-3-$

generating a deterioration of its terms of trade and consequently a penalty. The penalty is related to its trade dependency, as defined by the damage inflicted by a trade embargo. The threat that a default will invoke a penalty supports an equilibrium with international debt. The external indebtedness cannot be greater than the credit ceiling, proportional to the openness of the economy, as measured by the gains from trade.

In period one the economy is liberalized, and tariffs are eliminated. The public views the reform credibility as questionable, and expects the possibility of a policy reversal. We assume that the sectorial composition of public investment conveys a signal regarding the probability of policy reversal: higher public investment in exportable goods increases the public capital vested in the outward sector, reducing, thereby, the prospect for policy reversal. A key feature of the economy is the lack of complete markets, preventing the public from insuring against the policy risk. Agents are risk averse, and they act so as to maximize their expected utility. The policy maker sets policies and public investment so as to maximize the expected utility of the representative agent. The role of policies stems from the attempt to induce the private sector to internalize extemalities, and to provide for public investment that will recognize its signaling effect. 5

We characterize the equilibrium, deriving the optimal public investment and the private investment tax-cum-subsidy policies. We show that the signaling effect of public investment generates a positive extemality for public investment in the outward sector, and a negative extemality for public investment in the inward-oriented activity. Using the investment path with full credibility as the benchmark, we show that the signaling externality increases the optimal share of public relative to the private investment in the outward-oriented activity, and lowers that share in the inward-oriented activity. Thus, to overcome the lack of

5. Thus, the role of policies does not stem from asymmetric information. Calvo (1988) showed that mistaken beliefs about future policies act like a distortion, calling for policies. 
$-4-$

credibility the government biases the public /private capital share in favor of the outward sector, and against the inward sector.

We identify the need to tax private investment in the importable sector. The prospect of the imposition of a tariff in an economy that finances investment in terms of local bonds generates excessive investment in the inportable sector. This is the outcome of the drop in the ex-ante real interest rate facing a producer in the importable sector due to the expected tariff hike. Another reason for taxing investment in the importable sector is to account for the negative openness externality: inward investment makes the country more risky for external creditors, reducing the external credit ceiling. Applying the openness argument to the outward sector, it follows that one should subsidize investment in the outward-oriented sector.

A necessary condition for the implementation of these policies is that sectorial investment policies are feasible. This presumes that the policy maker has the ability to prevent the abusing of the preferential investment incentive system. To gain insight regarding the role of policies in economies where the authorities can not enforce sectorial policies, we contrast the equilibrium with sectorial private investment policies to the one obtained in the absence of these polices. We show that the elimination of sectorial private investment policy calls for a rise in the public/private capital ratio in the outward-oriented activities, and a drop in that ratio in the inward-oriented activities. In the presence of an external credit ceiling, the degree of risk aversion plays an important role in determining the magnitude (but not the nature) of the policies. A higher degree of risk aversion increases the magnitude of the above policies (i.e., it will increase the rates of private investment tax-cum-subsidy policies). To clarify the role of the integration with the international credit market, we compare the case where there is limited access to the international credit market with two extreme situations: no access versus unrestricted access to the international credit market. We show that cutting the country off the international credit market eliminates the openness externality, and thereby removes the need to subsidize private investment in the outward-oriented activity, and reduces the tax on private investment in the inward-oriented activities. Full access to the international credit market reduces further the tax on investment in the outward activity. We conclude that a 
switch from integrated credit markets toward partially integrated markets, where the developing country faces a credit ceiling, implies that liberalization efforts should be supplemented with more activist private investment tax-cum-subsidy policies, whose purpose is to encourage outward orientation and discourage inward orientation.

In section 2 we specify the model. In section 3 we characterize the behavior of the private sector. In section 4 we infer the value of the public investment and the tax-cumsubsidy policies under different scenarios. First, we assume that the policy maker determines the public investment and activates private investment incentives in the form of sectorial investment tax-cum-subsidy policies. In the second scenario the only role of the policy maker is determining the public sector's investment. In section 5 we analyze the dependency of the optimal policies on the degree of risk aversion and the access to the intemational credit market. Section 6 closes the paper with concluding remarks.

\section{The economy}

We describe the economy by reviewing output, preferences, the linkages to the intemational goods and credit market, and the nature of the policy uncertainty.

\subsection{Output}

Consider a two sector economy, composed of activities $\mathrm{X}$ and $\mathrm{Y}$, where output at time $\mathrm{t}$ is given by

(1) $\mathrm{x}_{\mathrm{t}}=\mathrm{a}_{\mathrm{x}}\left[\left(\mathrm{K}_{\mathrm{t} ; \mathrm{x}}^{\mathrm{p}}\right)^{\gamma}+\lambda\left(\mathrm{K}_{\mathrm{t} ; \mathrm{x}}^{\mathrm{g}}\right)^{\gamma / \beta / \gamma}\right.$

(2) $\mathrm{Y}_{\mathrm{t}}=\mathrm{a}_{\mathrm{y}}\left[\left(\mathrm{K}_{\mathrm{t} ; \mathrm{y}}^{\mathrm{p}}\right)^{\gamma}+\lambda\left(\mathrm{K}_{\mathrm{t} ; \mathrm{y}}^{\mathrm{g}}\right)^{\gamma}\right]$, for $\gamma \leq 1,0 \leq \beta \leq 1,0<\lambda$,

where $\left(\mathrm{K}_{\mathrm{t} ; \mathrm{j}}^{\mathrm{p}} ; \mathrm{K}_{\mathrm{t} ; \mathrm{j}}^{\mathrm{g}}\right\}$ denote private and public investment at time $\mathrm{t}$ in sector $\mathrm{j}(\mathrm{j}=\mathrm{x}, \mathrm{y})$. Both private and public capital are used in the production process. The coefficient $\lambda$ measures the 
$-6-$

efficiency of public capital relative to private capital. A unitary coefficient indicates no efficiency bias, and a lower value implies greater efficiency bias in favor of private capital. The elasticity of substitution between the two types of capital is given by $1 /(1-\gamma) .6$ The second period capital stock is the sum of the first period capital, adjusted downward to account for depreciation, plus the first period investment. For exposition simplicity, we assume henceforth zero depreciation.

\subsection{Preferences}

The representative agent maximizes the value of expected utility function, of the constant absolute risk aversion variety,

(3) $\quad V=-\exp -\tau(1+\rho)\left(U_{1}+\frac{1}{1+\rho} U_{2}\right\}$.

$U_{t}(t=1,2)$ denotes the periodic utility, assumed to be of a Cobb-Douglas type:

(4) $\quad \mathrm{U}_{\mathrm{t}}=\left(\mathrm{C}_{\mathrm{t} ; \mathrm{x}}\right)^{1-\alpha}\left(\mathrm{C}_{\mathrm{t} ; \mathrm{y}}\right)^{\alpha} /\left[(1-\alpha)^{1-\alpha}(\alpha)^{\alpha}\right], 0 \leq \alpha \leq 1$.

A useful feature of the utility function specified in (3) is the separation of the degree of risk aversion from the degree of intertemporal substitutability. This is done at the cost of forgoing the linearity advantage. 7

6. To simplify exposition, we assume the same elasticities for both sectors. It can be shown that the key results hold even if elasticities differ across sectors.

7. In the absence of uncertainty, the utility specified in our paper is equivalent to the time additively separable utility, where the subjective discount factor is $\rho$. With uncertainty, the degree of risk aversion is measured by $\tau$. 


\subsection{Linkages with the international market}

We assume that the external relative price of the two goods is one. The country has a comparative advantage in the production of good $X .8$ The international interest rate is given by $r^{*}$. The access of the country to the intemational credit market is restricted by its perceived openness, which determines the ability and the willingness of the country to service its extemal debt. A country that will default on its external debt may face trade restraints, generating a deterioration of its terms of trade and, consequently, a penalty. Let us denote the percentage deterioration of the terms of trade by $e$, and the volume of exports in the absence of impediments to trade by $\Omega .9$ In equilibrium, the country's repayment to its lenders is bounded by the penalty associated with default, and the repayment occurs to avoid the penalty. 10 Applying the properties of the Cobb-Douglas utility, we find that the willingness to provide extemal credit $\left(\mathrm{F}^{*}\right)$ to the economy is governed by the condition that

$$
\text { (5) } \quad \mathrm{F}^{*}\left(1+\mathrm{r}^{*}\right) \leq \mathrm{e} \Omega_{2}
$$

where

8. This assumption requires the relative productivity ratio $a_{x} / a_{y}$ to be large enough such that the autarky relative price of good $x$ relative to good $y$ is smaller than the international relative price.

9. The parameter e measures the effectiveness of a trade embargo in affecting the terms of trade facing the economy.

10. For a discussion regarding bargaining and sovereign debt see Bulow and Rogoff (1989) and the references there. For a discussion regarding the role of openness in determining the bargaining outcome see Aizenman (1989). 
(6)

$$
\Omega_{2}=\alpha X_{2}-(1-\alpha) Y_{2} \cdot 11
$$

The right hand side of (5) is the penalty associated with the deterioration of the terms of trade, equals to the deterioration of the terms of trade times the level of exports, approximated by $\Omega_{2}$. Consequently, the trade dependency of the economy is determining the credit available to the economy. Throughout the first part of the paper we will assume that the country is credit constrained, and thus (5) holds with equality. In Section 4 we relax this assumption in order to explore the consequences of the presence of credit rationing on the desirable policies.

\subsection{The policy uncertainty}

A salient characteristic of developing countries is the relative instability of their policies, including the instability of commercial policy. One can interpret this as the outcome of a struggle between pressure groups whose relative powers vary over time, as well as due to attempts to adjust to domestic and foreign shocks by manipulating the commercial policy. 12 In this paper we focus on investigating the consequences of credibility problems facing a policy

11. Applying the properties of the Cobb-Douglas function we get the the second period utility in the absence of default is $U_{2}=X_{2}+Y_{2}-F^{*}\left(1+r^{*}\right)$. In case of default the

$$
\mathrm{X}_{2}+\mathrm{Y}_{2}(1+\mathrm{e})
$$

utility is $\mathrm{U}_{2}=\frac{}{(1+\mathrm{e})^{\alpha}}$. The exact credit ceiling is obtained by finding the value of $\mathrm{F}^{*}$ that will equate these two expressions. The exact penalty is given by [1- $\left.(1+e)^{-\alpha}\right] X_{2}-\left[1-(1+e)^{1-\alpha}\right] Y_{2}$. The term e $\Omega_{2}$ in $(5)$ is the first order approximation to the exact credit ceiling.

12. For a review of the experience of developing countries see Edwards (1989), Choksi, Michaely and Papageorgiou (1990) and the references there. 
maker who enacts a trade liberalization. At period 1 the policy maker liberalizes the economy, eliminating tariffs and other trade impediments. The public attaches a probability $(\phi)$ to the success of the liberalization, in which case there will be free trade in period 2, and expects that with portability $(1-\phi)$ the liberalization will fail and a tariff rate of $\theta$ will be instated in period 2 . We denote the success and the failure states by $s$ and $f$, respectively. The success probability $(\phi)$ is affected by present policies. The public infers from the public investment profile the degree to which the policy maker will have vested interest in preserving the liberalization. Specifically, we assume that public investment in sector $\mathrm{X}$ will increase the probability of successful liberalization, by increasing the cost for the policy maker of reinstating the tariff. The opposite applies to sector $y$. Thus,

$\phi=\phi\left(\mathrm{K}_{2 ; \mathrm{x}}^{\mathrm{g}} ; \mathrm{K}_{2 ; \mathrm{y}}^{\mathrm{g}}\right)$, with $\phi_{1}^{\prime}>0 ; \phi_{2}^{\prime}<0$ (where $\phi_{\mathrm{j}}^{\prime}$ denotes the partial derivative with respect to argument $\mathrm{j})^{13}$. There are two complementary dimensions for the signaling. First, it changes the composition of the capital stock to be inherited by future administrations, affecting, thereby, the cost-benefit of policy reversal in the future. Second, if the present policy maker will survive into the future, the present investment policy may signal his type.

\section{The allocation of resources}

We characterize the allocation of resources by considering the problem confronting the representative agent who faces two intertemporal margins: the determination of savings (in the form of the purchase of bonds, denominated in terms of the domestic good), and the magnitude of investment in activities $x$ and $y$. For ease of tractability, we solve these problems sequentially. In general, however, the representative agent solves these two margins simultaneously.

13. If private investment changes the probability of policy reversal, then $\phi=\phi\left(\mathrm{K}_{2 ; \mathrm{x}}^{\mathrm{g}} ; \mathrm{K}_{2 ; \mathrm{y}}^{\mathrm{g}} ; \mathrm{K}_{2 ; \mathrm{x}}^{\mathrm{p}} ; \mathrm{K}_{2 ; \mathrm{y}}^{\mathrm{p}}\right)$, with $\phi_{1}>0 ; \phi_{2}<0 ; \phi_{3}^{\prime}>0 ; \phi_{4}^{\prime}<0$. Our analysis can be readily extended to include this possibility. 


\subsection{The consumer's problem}

We denote by $\mathrm{H}_{\mathrm{I}}$ and $\mathrm{H}_{2}$ the consumer's first and second period income, and by $\mathrm{B}$ the first period savings. The resources devoted to consumption (in terms of the domestic good) are given:

(7) $\mathrm{Z}_{1}=\mathrm{H}_{1}-\mathrm{B} ; \mathrm{Z}_{2}=\mathrm{H}_{2}+\mathrm{B}(1+\mathrm{r})$.

Within the period, the consumer is allocating his consumption as to maximize a CobbDouglas utility. We denote by $\mathrm{U}_{2}$ Ifailure and by $\mathrm{U}_{2}$ Isuccess the utility in the event of failed and successful reform and find that,

(8) $\mathrm{U}_{\mathrm{I}}=\mathrm{Z}_{1}$

(9) $\mathrm{U}_{2 \text { Ifailure }}=\frac{\mathrm{Z}_{2}}{1+\bar{\theta}} ; \mathrm{U}_{2 \text { |success }}=\mathrm{Z}_{2}$,

where $1+\dot{\theta}$ is the price index deflating income when the tariff is set at rate $\theta .14$ Using the properties of the Cobb-Douglas utility function, it is evident that $\bar{\theta}$ depends positively on the tariff rate, and is zero in the abschce of tariffs.

Applying (8)-(9) to (3) we obtain the expected utility of the representative agent:

14. Direct derivation reveals that $\bar{\theta}=(1+\theta)^{\alpha}-1-\alpha \theta /(1+\theta)^{1-\alpha}$. In deriving this result, we assume that the tariff proceeds are reimbursed to the public in the form of lump sum transfers. If these proceeds are used to finance fiscal outlays that do not affect the private utility, $\bar{\theta}$ will be larger $\left[\bar{\theta}=(1+\theta)^{\alpha}-1\right]$, accounting for an adverse income effect of the tax hike. 
(10)

$-\exp \left[-\tau(1+\rho)\left(\mathrm{H}_{1}-\mathrm{B}\right)\right]\left(\phi \exp \left[-\tau\left(\mathrm{H}_{2}+\mathrm{B}(1+\mathrm{r})\right)\right]+(1-\phi) \exp \left[-\tau \frac{\left(\mathrm{H}_{2}+\mathrm{B}(1+\mathrm{r})\right)}{1+\bar{\theta}}\right]\right)$

The consumer demands bonds such as to maximize (10), yielding the condition characterizing the 'risk premium' associated with the future policy unccrtainty:

(11) $\frac{r-\rho}{1+\rho}=\ddot{\theta} \frac{(1-\phi) \psi}{(1+\dot{\theta}) \phi+(1-\phi) \psi}$,

where $\psi=\exp \left(\tau \mathrm{Z}_{2} \frac{\bar{\theta}}{1+\bar{\theta}}\right)$. The term $\psi$ measures the utility gap introduced by the possibility of policy reversal, defined by the ratio of the utility attainable in the event of successful and failed stabilization (i.e., $\psi=\exp \left[-\tau Z_{2}\right] / \exp \left[-\tau \frac{Z_{2}}{1+\dot{\theta}}\right]$ ). The supply of saving may be inferred from (11): it can be shown that lower credibility of the trade reform (either due to a lower probability of a success, or a higher tariff rate) will shift the supply of saving leftward, depress savings 15 . If the reform is credible, the domestic interest rate equals the rate of time preferences, reflecting the assumption that the only source of uncertainty is the possibility of policy reversal.

15. Applying (11) we get that the condition for an internal equilibrium with positive saving is that

$r>\rho+(1+\rho) \bar{\theta} \frac{(1-\phi) \psi_{0}}{(1+\bar{\theta}) \phi+(1-\phi) \psi_{0}}$, where $\psi_{0}=\exp \left(\tau\left\{Y_{2}+X_{2}\right\} \frac{\bar{\theta}}{1+\bar{\theta}}\right)$.

Henceforth we assume that the marginal product of capital is high enough so that this condition is satisfied. 
Equation (11) highlights the factors determining the gap between the interest rate and the rate of time preference: it depends positively on the degree of risk aversion $(\tau)$, and the probability and magnitude of policy reversal (as measured by $1-\phi$ and $\bar{\theta}$, respectively).

\subsection{The investor's problem}

We focus now on the investor's problem. Suppose that the entrepreneur finances investment by issuing bonds. An investment of $I_{y}$ in activity $Y$ will generate an income profile of

(12) $\mathrm{Z}_{2 \text { Isuccess }}=\mathrm{Y}_{2}-(1+\mathrm{r})\left(1-\mathrm{s}_{\mathrm{y}}\right) \mathrm{I}_{\mathrm{y}} ; \mathrm{Z}_{2 \text { Ifailure }}=(1+\theta) \mathrm{Y}_{2}-(1+\mathrm{r})\left(1-\mathrm{s}_{\mathrm{y}}\right) \mathrm{I}_{\mathrm{y}}$ where the investment is subsidized at a rate of $s_{y}$. The investor's expected utility is given by

$$
\left(12^{\prime}\right)-\exp \left[-\tau(1+\rho) Z_{1}\right]\left\{\phi \exp \left[-\tau Z_{2 \text { |success }}\right]+(1-\phi) \exp \left[-\tau \frac{Z_{2 \text { lfailure }}}{1+\dot{\theta}}\right]\right\}
$$

Maximizing (12') with respect to the investment $I_{y}$ yields the condition determining the optimal investment in sector $y$. While the first order condition tends to be tedious, it is simplified considerably by applying the condition determining the domestic interest rate (11), yielding:

(13) $\operatorname{MPK}{ }_{y}^{p}=(1+r)\left(1-s_{y}\right)\left(1-\frac{\theta(r-\rho)}{(1+\rho) \bar{\theta}+\theta(r-\rho)}\right)$. 
$-13-$

Optimal investment requires that the marginal product of capital (denoted by MPK ${ }_{y}$ ) is equated to the cost of capital 16. Recall that the investment is financed by bonds denominated in terms of the domestic good, $x$. A tariff at a rate of $\theta$ reduces the real interest rate facing the investor in sector $y$. This effect is captured by the last term in (13). The tariff effect on the cost of capital is sector specific, and is absent for sector $x$. Applying the same procedure we obtain that the investment in sector $\mathrm{x}$ is govemed by the condition that

$$
\operatorname{MPK}_{x}^{p}=(1+r)\left(1-s_{x}\right) \text {. }
$$

\section{The role of policies}

We tum now to characterize optimal policies. We derive first the conditions determining the optimal allocation of resources. This allows us to identify several extemalities. We then derive the value of the optimal sectorial investment tax-cum-subsidy policies by finding the tax rates that will induce the private sector to intemalize the extemalities. Finally, we characterize the relative shares of public and private capital, and evaluate the dependency of taxes on the presence of sectorial policies.

\subsection{The optimal resources allocation}

The policy maker determines investment and policies such as to maximize the expected utility of the representative individual. We assume the presence of lump sum taxes and transfers, such that the periodic budget constraints facing the representative agent are

16. The condition for an interior solution with positive investment is that the marginal product of capital in the absence of new investment exceeds the cost (the right hand side of (13)). Hencefortl we assume that the productivity of capital is high enough such that this condition is satisfied. 


$$
\begin{aligned}
& \text { (15) } C_{1 ; x}+C_{1 ; y}=X_{1}+Y_{1}-I_{1 ; x}^{p}-I_{1 ; x}^{g}-I_{1 ; y}^{p}-I_{1 ; y}^{g}+F^{*} \\
& \text { (16a) } C_{2 ; f ; x}+(1+\theta) C_{2 ; f ; y}=X_{2}+(1+\theta) Y_{2}-D^{*}+T_{2} \text {, and } \\
& \text { (16b) } C_{2 ; s ; x}+C_{2 ; s ; y}=X_{2}+Y_{2}-D^{*}
\end{aligned}
$$

where $F^{*}$ is the external credit, $D^{*}$ is the repayment of the external debt, and $T_{2}$ is the lump sum transfer rebating the tariff proceeds (equals to $\theta\left[\mathrm{C}_{2 ; \mathrm{y}}-\mathrm{Y}_{2}\right]$ ). Equations (16a) and (16b) correspond to the liberalization success and failure possibilities. To simplify, we assume a zero initial external debt. The demand for external credit is large enough, such that the credit ceiling is binding:

$$
\text { (17) } \mathrm{F}^{*}=\left[\alpha \mathrm{X}_{2}-(1-\alpha) \mathrm{Y}_{2}\right] /\left(1+\mathrm{r}^{*}\right) ; \quad \mathrm{DB}^{*}=\mathrm{F}^{*}\left(1+\mathrm{r}^{*}\right)
$$

Applying $(8,9,15,16)$ to $(3)$ we obtain that the expected utility of the representative agent is given by:

$$
\text { (18) }-\exp \left[-\tau(1+\rho) Z_{1}\right]\left\{\phi \exp \left[-\tau Z_{2}\right]+(1-\phi) \exp \left[-\tau \frac{Z_{2}}{1+\dot{\theta}}\right]\right\},
$$

where $Z_{t}(t=1,2)$ denotes the consumption at period $t$, measured in terms of the domestic good:

$$
\begin{aligned}
& \text { (19) } \mathrm{Z}_{1}=\mathrm{X}_{1}+\mathrm{Y}_{1}-\mathrm{I}_{1 ; \mathrm{X}}^{\mathrm{p}}-\mathrm{I}_{1 ; \mathrm{X}}^{\mathrm{g}}-\mathrm{I}_{1 ; \mathrm{y}}^{\mathrm{p}}-\mathrm{I}_{1 ; \mathrm{y}}^{\mathrm{g}}+\mathrm{F}^{*} \text {; } \\
& \text { (20) } \mathrm{Z}_{2}=\mathrm{X}_{2}+\mathrm{Y}_{2}-\mathrm{DB} \mathrm{B}^{*}
\end{aligned}
$$




$$
-15-
$$

where $\mathrm{F}^{*}$ and $\mathrm{DB}^{*}$ are given by (17). Optimal policies are derived in three stages. First, we characterize the optimal investment by optimizing (18) with respect to $\left(\mathrm{I}_{1 ; x^{\mathrm{p}}}^{\mathrm{p}} ; \mathrm{I}_{1 ; \mathrm{x}}^{\mathrm{g}} ; \mathrm{I}_{1 ; y}^{\mathrm{p}} ; \mathrm{I}_{1 ; y}^{\mathrm{g}}\right)$.

This yields four tedious equations that tie the marginal product of investment with its social cost, expressed in terms of the utility ratio, $\psi$. To gain further insight it is constructive to express the utility ratio in terms of the domestic interest rate, using the first order condition determining the interest rate (11). After tedious collections of terms we can reduce the first order conditions to

$$
\begin{aligned}
& \operatorname{MPK}_{y}^{p}=\frac{1+r}{1-\bar{e}(1-\alpha)\left(r-r^{*}\right)} \\
& \operatorname{MPK}_{y}^{g}=\frac{1+r}{1+k \phi_{y}^{\prime}-\bar{e}(1-\alpha)\left(r-r^{*}\right)}
\end{aligned}
$$$$
\text { (23) }
$$

$$
\begin{aligned}
\operatorname{MPK}_{X}^{\mathrm{p}} & =\frac{1+\mathrm{r}}{1+\overline{\mathrm{e}} \alpha\left(\mathrm{r}-\mathrm{r}^{*}\right)} \\
\mathrm{MPK}_{\mathrm{X}}^{\mathrm{g}} & =\frac{1+\mathrm{r}}{1+k \phi_{\mathrm{X}}^{\prime}+\overline{\mathrm{e}} \alpha\left(\mathrm{r}-\mathrm{r}^{*}\right)}
\end{aligned}
$$

where $\mathrm{k}=\frac{(\psi-1)(1+\mathrm{r})}{(1+\rho) \tau(\phi+(1-\phi) \psi)}>0$ and $\overline{\mathrm{e}}=\frac{\mathrm{e}}{1+\mathrm{r}^{*}}$.

Equations (21) and (22) characterize the optimal private investment, and (23) and (24) the optimal public investment. Optimality requires equating the marginal product of capital to the marginal social cost. The marginal social cost adjusts the interest rate factor $(1+r)$ to reflect the extemalities introduced by the investment. Two types of extemalities are relevant. First, the investment will affect the openness of the economy, changing, thereby, the credit ceiling and generating an externality. This externality is proportional to the gap between the domestic and the foreign interest rate $\left(r-r^{*}\right)$, times the resultant change in the credit ceiling ( $\overline{\mathrm{e}} \alpha$ and $-\overline{\mathrm{e}}(1-\alpha)$ for sectors $\mathrm{X}$ and $\mathrm{Y}$, respectively). An outward-oriented investment generates a positive externality, reducing, thereby, the social cost of capital invested in 
exportable (the opposite applies to the inward-oriented investment). The openness extemality applies to both the public and the private investment. 17

The second type of extemality relates to the signaling effects of public investment, affecting the probability of a credible liberalization. Public investment in outward-oriented activities increases the prospect of successful trade liberalization: it increases the vested public interest in these activities, raising, thereby, the cost of policy reversal. This generates a positive extemality, proportional to the raise in the probability of successful liberalization $\left(\phi_{X}>0\right)$ times a measure of the distortion introduced by the policy uncertainty, as depicted by $\mathbf{k}$. The policy uncertainty distortion $\mathbf{k}$ is proportional to the gap between the utility attainable with successful liberalization and the utility attainable with policy reversal, as measured by $\psi-1$. The policy extemality operates in the opposite direction for investment in the inwardoriented sector: public investment in that sector will reduce the probability of a successful liberalization, because it will reduce the losses (or increase the gains) from policy reversal.

\subsection{Optimal sectorial investment tax-cum-subsidy policies}

The optimal investment tax-cum-subsidy policies are derived by solving the values of the $s_{x}$ and $s_{y}$ that equates the private sector's optimality condition with that of the policy maker [equations (13) to (21) and (14) to (22)], yielding:

17. If the extemalities affecting the investment in sector $y$ are powerful enough, we may end up in a comer solution, where no investment will occur in that sector, corresponding to the case where the right hand side of (21) or (23) is negative. Hencefortl, we will assume that these externalities are not too large, such that we observe an intemal equilibrium. All the key results can be shown to apply for the altemative case. 
$-17-$

$$
\text { (25) } s_{y}=-\frac{\overline{\mathrm{e}}(1-\alpha)\left(\mathrm{r}-\mathrm{r}^{*}\right)+\frac{\theta}{\bar{\theta}}(\mathrm{r}-\rho) /(1+\rho)}{1-\overline{\mathrm{e}}(1-\alpha)\left(\mathrm{r}-\mathrm{r}^{*}\right)} ; \quad \mathrm{s}_{\mathrm{x}}=\frac{\overline{\mathrm{e}} \alpha\left(\mathrm{r}-\mathrm{r}^{*}\right)}{1+\overline{\mathrm{e}} \alpha\left(\mathrm{r}-\mathrm{r}^{*}\right)} \text {. }
$$

Optimality calls for subsidizing private investment in the outward-oriented activity, and taxing private investment in the inward activity. Investment in inward activities should be taxed due to two reasons: first, to induce producers to intemalize the cost introduced by the external credit ceiling; second, to reduce the tendency of the private sector to over-invest in the outward activities. The prospect of commercial policy reversal in an economy where the investment is financed by local bonds (whose yield is denominated in terms of the domestic good) introduces a distortion. A tariff hike generates an asymmetric response of the producers real interest: it will reduce the real interest rate for investment in the inward-oriented activity relative to the real interest rate for investment in the outward-oriented activity. This generates a bias towards private investment in the inward-oriented activity, a bias that is the outcome of the policy reversal and the financial structure of the economy. This bias is a distortion, whose elimination calls for a tax on investment in the inward sector, at a rate that depends positively on the gap between the domestic interest rate and the rate of time preferences. Consequently, factors that increase the domestic interest rate, like a debt crisis that truncates the access of the developing economy to the intemational credit market, will increase the distortion introduced by the lack of credibility of the trade reform. The lack of full credibility of the trade reform generates the prospect for immiserizing growth. 18 The purpose of the tax is to prevent such a growth.

18. See Brecher and Diaz Alejandro (1977) and the references there for immiserizing growth in a non-stochastic model. 


\subsection{The relative shares of public and private capital}

Applying (21-24) to (1) and (2) we may infer the ratio of the desirable public relative to the private capital stock in the two activities:

$$
\begin{aligned}
& \frac{\mathrm{K}_{\mathrm{t} ; \mathrm{x}}^{\mathrm{g}}}{\mathrm{K}_{\mathrm{t} ; \mathrm{x}}^{\mathrm{p}}}=\left[\lambda\left\{1+\frac{\mathrm{k} \phi_{\mathrm{x}}^{\prime}}{1+\overline{\mathrm{e} \alpha\left(\mathrm{r}-\mathrm{r}^{*}\right)}}\right\}\right]^{1 /(1-\gamma)} \\
& \frac{\mathrm{K}_{\mathrm{t} ; \mathrm{x}}^{\mathrm{g}}}{\mathrm{K}_{\mathrm{t} ; \mathrm{x}}^{\mathrm{p}}}=\left[\lambda\left\{1+\frac{\mathrm{k} \phi_{\mathrm{y}}^{\prime}}{1-\overline{\mathrm{e}}(1-\alpha)\left(\mathrm{r}-\mathrm{r}^{*}\right)}\right\}\right]^{1 /(1-\gamma)} .
\end{aligned}
$$

A useful benchmark is the case where there is no efficiency bias in favor of either types of capital $(\lambda=1)$, and there are no credibility externalities $\left(\phi_{x}^{\prime}=\phi_{y}^{\prime}=0\right)$. In that case, an equal amount of public and private capital will be used in both activities. The introduction of credibility externalities generates a bias in favor of public investment in the outward-oriented sector (relative to the private investment), and against public investment in the inwardoriented sector. As one may expect, relative inefficiency of public investment $(\lambda<1)$ will generate a bias in favor of private investment. 19

19. The information conveyed in (26) and (27) refer to the public/private capital ratios. The levels of the capital stock may be solved by applying (1), (2) and (21-24). It can be shown that the credibility externality will increase the level of public investment in the outward-activities and will reduce the level of public investment in the inward-activities. The correlation between pubic and private investment is positive if the substitutability of the two types of capital is relatively low $(\gamma<\beta)$. In that case, the credibility externality increases the level of private investment in the outward activities and reduces the private investment in the inward activities. The opposite applies if the substitutability is high enough $(\gamma>\beta)$. 
So far we have assumed that the policy maker has enough instruments to discriminate among the various activities, in the form of sectorial policies. This presumes the ability to monitor private investment, preventing the abuse of subsidics by over-reporting investment, or shifting funds from the designated investment towards other projects. These assumptions are not always accurate, and it is useful to contrast the above equilibrium to the one obtained in the absence of these polices. Specifically, let us assume that the policy maker does not apply the investment tax-cum-subsidy policies. Following the logic of our previous discussion, we can characterize the nature of the new equilibrium. It is easy to show that the conditions for the private sector's investment are given by (13)-(14), for the case where $s_{y}=s_{x}=0$. The optimal public investment continue to be characterized by (23)-(24). The ratios of the public/private investment are now given by

$$
\frac{\mathrm{K}_{\mathrm{t} ; \mathrm{x}}^{\mathrm{g}}}{\mathrm{K}_{\mathrm{t} ; \mathrm{x}}^{\mathrm{p}}}=\left[\lambda\left\{1+\mathrm{k} \phi_{\mathrm{x}^{\prime}}+\overline{\mathrm{e}} \alpha\left(\mathrm{r}-\mathrm{r}^{*}\right)\right\}\right]^{\mathrm{I} /(\mathrm{I}-\gamma)}
$$

$$
\frac{\mathrm{K}_{\mathrm{t} ; \mathrm{y}}^{\mathrm{g}}}{\mathrm{K}_{\mathrm{t} ; \mathrm{y}}^{\mathrm{p}}}=\left[\lambda\left\{\mathrm{I}+\mathrm{k} \phi_{\mathrm{y}^{-}}-\overline{\mathrm{e}}(1-\alpha)\left(\mathrm{r}-\mathrm{r}^{*}\right)\right\}\right]^{1 /(1-\gamma)} .
$$

Comparison of $(26)-(27)$ and $\left(26^{\prime}\right)-\left(27^{\prime}\right)$ reveals that the elimination of sectorial private investment policy prevents the internalization of the openness externality by the private sector, necessitating a compensating adjustment of the public investment. This adjustment works toward magnifying the biases of public relative to private investment, identified in equations (26) and (27). It calls for a rise in the public/private capital ratio in the outward-oriented activities, and a drop in that ratio in the inwards-oriented activities. 
5. Policies, risk aversion and the access to the intemational credit market

It is constructive to conclude the analysis by reviewing the relevance of the degree of risk aversion and the nature of the access to the international credit market on the policy design. The degree of risk aversion plays an important role in determining the domestic interest rate. From (11) we infer that a higher degree of risk aversion $(\tau)$ increases the domestic interest rate, whose values are in between

$$
r_{\mid \tau=0}=\rho+\dot{\theta}(1+\rho) \frac{1-\phi}{1+\dot{\theta} \phi} \text {; and } r_{\mid \tau \rightarrow \infty}=\rho+\dot{\theta}(1+\rho) .
$$

Note that the degree of risk aversion affects the domestic interest rate, which in turn affects all the policy variables. Applying (25-27) we infer that a higher degree of risk aversion will increase the subsidy called for outward investment, and the tax on inward investment. These results are summarized in Figure 1, where the bold lines (curves $s_{x}$ and $s_{y}$ ) depict the dependency of the various policies and shares on the degree of risk aversion.

We tum now to evaluate the dependency of optimal policies on the access to the intemational capital market. Throughout the paper we assumed that the country is facing an endogenous credit ceiling, that depends positively on the openness of the economy. In such a world, the openness extemality influences policies. To clarify the role of the integration with the international credit market, it is constructive to compare this case with two extreme situations: no access, and unrestricted access to the intemational credit market. Formally, cutting off the country from the intemational credit market implies that the credit ceiling is zero. In terms of (25-27), $\overline{\mathrm{e}}$ equals zero. This eliminates the subsidy on private investment in the outward activities, and reduces the tax on private investment in the inward activities. In terms of Figure 1 , the doted lines (curves $s_{x}^{\prime}$ and $s_{y}^{\prime}$ ) depict the locations of the new curves.

Finally, suppose that the country has unrestricted access to the intemational capital market, dominated by risk neutral agents demanding an expected yield of $r^{*}$. This is equivalent to the elimination of the openness externality [setting $\bar{e}$ to zero in (25)-(27)] and 


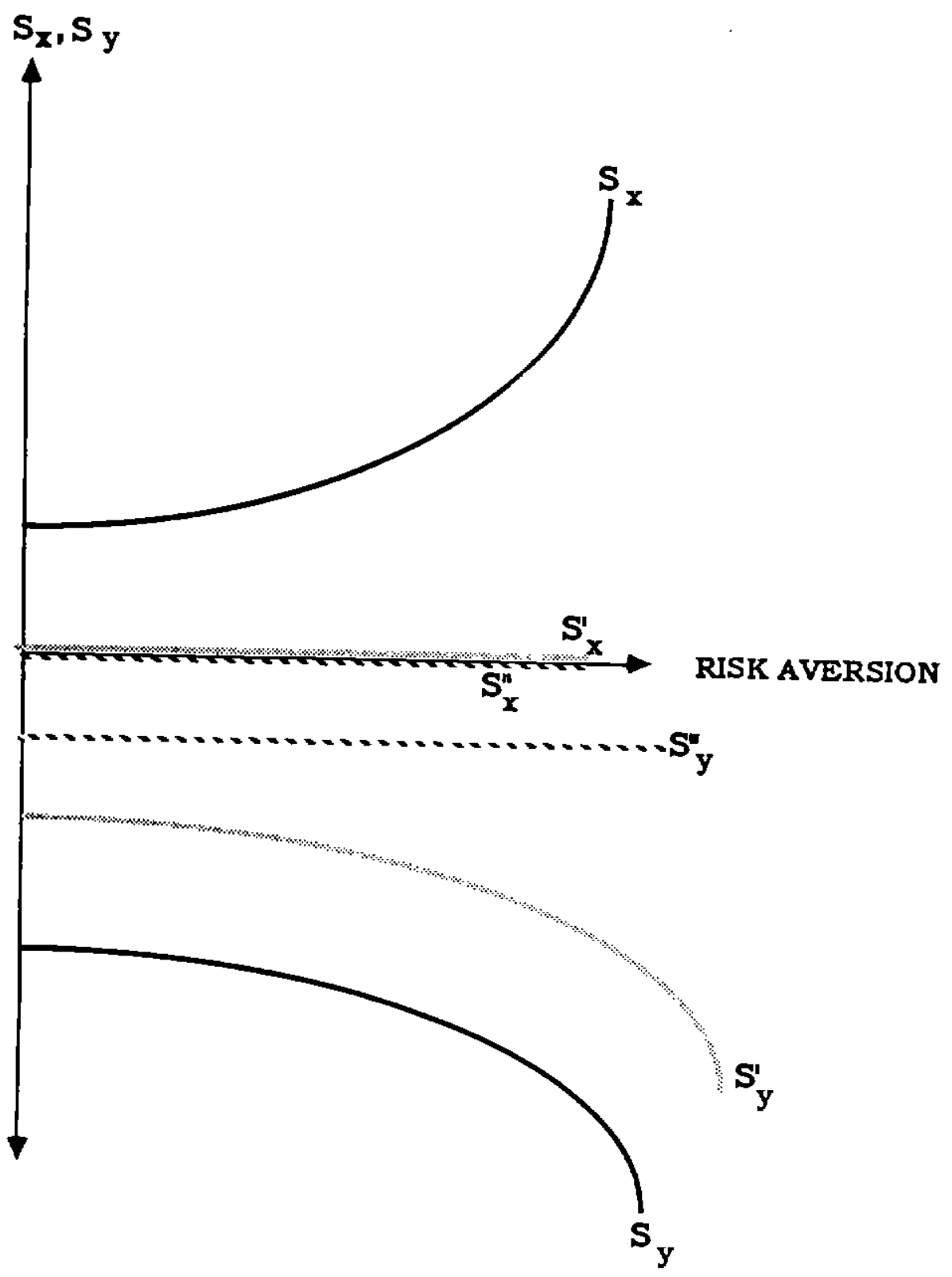

FIGURE 1

TAX-CUM-SUBSIDY POLICIES

LIMITED CAPITAL MARKETS INTEGRATION : $S_{\mathbf{x}}, \mathbf{S}_{\mathbf{y}}$ DISJOINT CAPITAL MARKETS : $\mathbf{S}_{\mathbf{x}}^{\prime}, \mathbf{S}_{\mathbf{y}}^{\prime}$

FULL CAPITAL MARKETS INTEGRATION: $\mathbf{S}_{\mathbf{x}}^{\mathbf{n}}$. $\mathrm{S}_{\mathbf{y}}^{\prime \prime}$ 
replacing the internal interest rate $r$ with the external one. It will have the consequences of eliminating the subsidy for private investment in the outward activity, and reducing the tax on the inward activity. The corresponding values are depicted by the broken lines (curves $s_{x}$ and $s_{y}^{\prime \prime}$ ) in Figure 1 .

\section{Concluding remarks}

This paper characterized the role of investment policies applicd to support a liberalization attempt. Rather than repeating the summary provided in the first section, we close the paper with interpretive remarks. The extemalities identified in this paper are generated due to the lack of a credible commitment mechanism that may overcome the time inconsistency problems. Ex ante, the optimal policy is to repay the external debt and to invoke a permanent liberalization. This policy, however, may lack complete credibility: Ex post there are forces that work toward partial default of external debt, and toward the reversal of trade liberation. Selective investment provides a commitment mechanism that may reduce the harmful consequences of time inconsistency. The lack of credibility of a reform generates a role for investment policies. In an economy with various potential projects, investment in projects that enhance the credibility of the reform should be encouraged. In the context of the present paper, these are outward-oriented projects that benefit from specific public investment. The identification of these investments may require detailed information beyond the information provided by the aggregate public investment. For example, investment in highways, telecommunications, and infrastructure in Tijuana and along the Mexican border with California may generate positive externalities. 20 It signals the willingness of the regime

20. Note that investment in infrastructure in Mexico City may lack these extemalities, since it is not specific and thus may enhance both inward- and outward-orientation. 
to support an outward orientation, to enhance the productivity of future direct investment by U.S. corporations in Mexico.21

While the details of the policies identified in the paper are model-dependent, the spirit of the key results can be shown to be general. First, the degree of integration with the external capital market plays an important role in the determination of policies. Second, reforms that lack complete credibility generate non-optimal investment due to the absence of complete markets, calling for tax-cum-subsidy policies. Third, there are linkages between public and private investment, whose form is related to the degree to which policies are credible, and the extent to which there are sectorial private investment policies. These results are relevant even in the restricted case of symmetric information among the policy maker and the public. They suggest that public investment may have a role as a signaling and commitment device, a role that deserves further empirical scrutiny.

21. More than half a million Mexicans are employed by foreign corporations in the Maquiladoras plants along the U.S.-Mexican border. The large direct investment in these plants illustrates that selective direct investment is highly profitable, even in the presence of debtoverhang. For further details regarding the welfare effect of direct investment in the presence of debt-overhang see Aizenman (1989). While the focus of our paper is on domestic investment, the message of the paper applies also to direct investment: higher credibility of the trade reform will enhance this type of investment. 
Appendix A

In order to verify the role of private and public investment in accounting for the growth rate, we regressed the growth rate on the private and public investment rate. This was done for the 23 countries studied by Greene and Villanueva (1990). The regression results are summarized in Table 1

Table 1

Growth rates, and public and private investment

Dependent variable: Growth rates

Explanatory variables

$\begin{array}{lllll}\text { Intercept } & \text { Public investment } & \text { Private investment } & \overline{\mathrm{R}}^{2} & \text { S.E. } \\ -1.926 & -.058 & .319 & .359 & 1.785\end{array}$

\section{Notes}

The data source is Pfefferman and Madarassy (1989). Number of countries: 23. All observations are yearly averages over the period 1975-1987. Two asterisks denote significance at $1 \%$ level.

Figure 2 plots the association of growth and private and public investment rates. The bold line is the regression line, whereas the other two lines correspond to the $95 \%$ confidence limits for the slope of the regression line. 

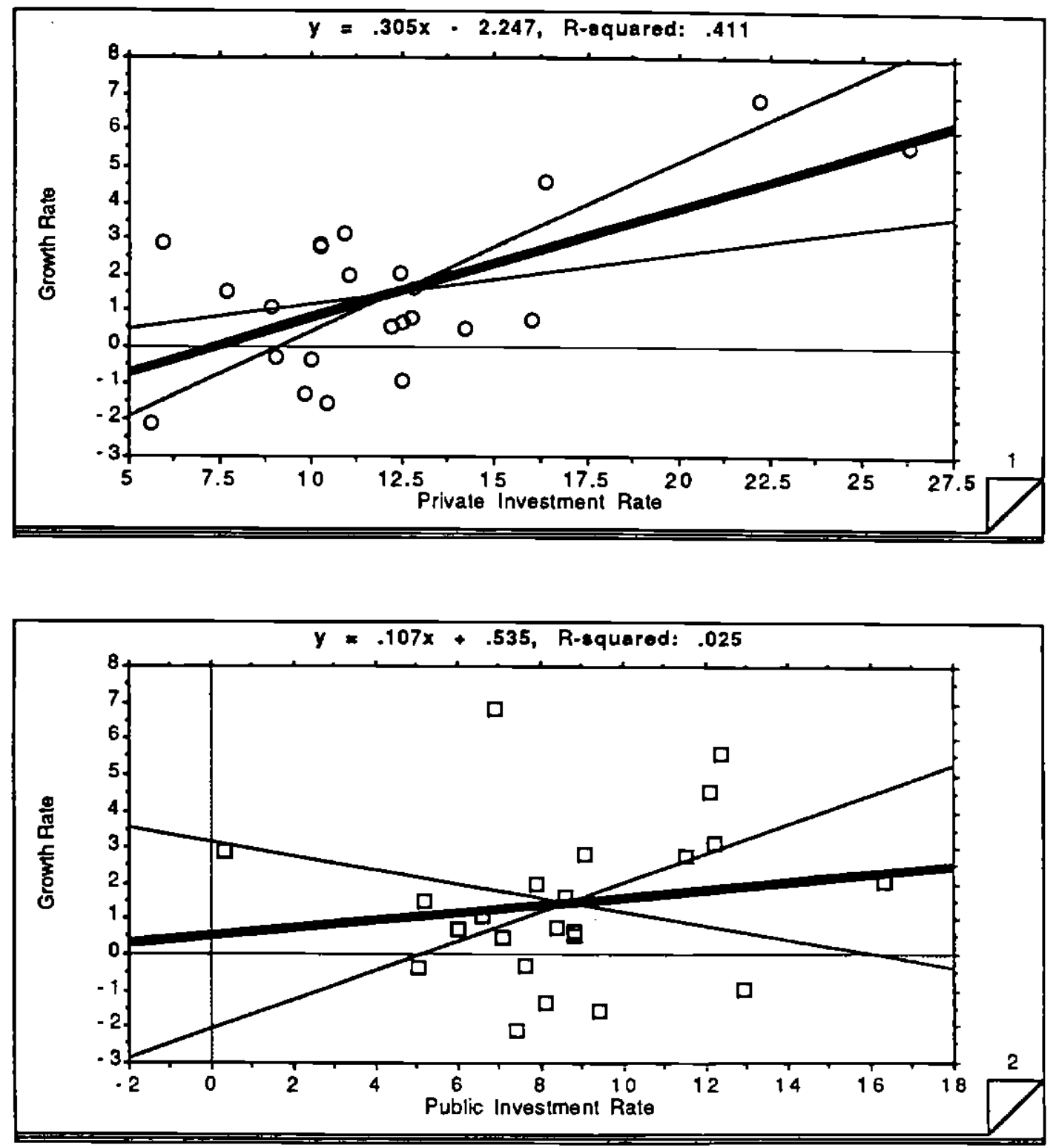

FIGURE 2 
Aizenman, Joshua, "Inward versus outward growth orientation in the presence of country risk," 1989, forthcoming, Econemica.

"Trade Dependency, bargaining and external debt," 1989, forthcoming, Loumal of Intemational Economics.

Blejer, Mario I. and Mohsin S. Khan, "Government policy and private investment in developing countries," IME Staff Papers, June 1984, 31, $379-403$.

Bulow I. Jeremy and Rogoff Kenneth , "A Constant recontracting model of sovereign debt," Joumal of Political Economy, 1989, 97, $155-78$.

Brecher Richard A. and Carlos F. Diaz Alejandro, "Tariffs, Foreign Capital and immiserizing Growth," Joumal of Intemational Economics, 1977, 7, 317-322.

Calvo, A. Guilermo, "Credibility and Economic Policy," manuscript presented at the conference Spain and the European Monetary System, 1988.

Choksi Armeane, Michaely Michael, and Demetris Papageorgiou, (edts.) Liberalizing Foreign Trade, Basil Blackwell, forthcoming, 1990.

Dixit, Avinash, "Ireversible investment with price ceilings," manuscript, Princeton University, October 1989.

Dombusch, Rudiger, "Notes on credibility and stabilization," NBER Working paper No. 2970, December 1988.

Edwards, Sebastian, Real Exchange Rates, Deyaluation, and Adjusment, MIT press, 1989.

Greene Joshua and Delano Villanueva, "Private investment in developing countries: an empirical analysis," 1990, forthcoming, MME Staff Papers.

Kahn, Mohsin S. and Carmen Reinhart, "Private investment and economic growth in developing countries," World Development , January 1990, 19-27.

Pfefferman, Guy and Andrea Madarassy, "Trends in private investment in 30 developing countries," IFC Economics Department Discussion Paper, World Bank Group, July 1989.

Pyndick, Robert S., "Irreversible investment, capacity choice and the value of the firm," American Economic Review 78 (5), December 1988.

Rodrik, Dani, "Promises, promises: credible policy reform via signaling," Economic Journal, September 1989. van Wijnbergen, Sweder, "Trade reform, aggregate investment, and capital flight," Economic Letters, 1985, 19, $369-72$. 